\title{
Mechanical Analysis of Stayed Bridge
}

\author{
Chen Tie $^{*}, 1,2$ and Zhou Ruichuan ${ }^{3}$
}

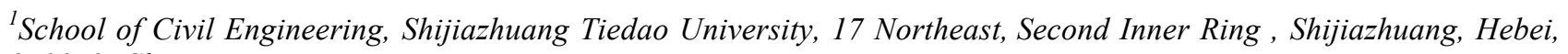
050043, China

${ }^{2}$ Key Laboratory of Roads and Railway Engineering Safety Control of Ministry of Education, Shijiazhuang Tiedao University, Hebei, 050043, China

${ }^{3}$ Shijiazhuang Tiecheng Bridge Engineering Testing Co., Ltd., USA

\begin{abstract}
Cable stayed bridge, also known as the cable-stayed bridge is of box girder with many cable directly to the towers is a kind of bridge, is by the pressure of the tower, tension of cable and bending bearing beams of a structure system. It can be considered as a continuous beam of multi span elastic supports for the cable instead of a pier. It can reduce the moment of the beam, reduce the height of the building, it reduce the weight of the structure and save the material. Stayed Bridge is a new form of bridge structure, The bridge structure special and complex forces, The deck transverse load and live load is to balance by tilting tower, By the general theory to analyze the cable-stayed bridge stayed bridge, The key is to consider the main tower tilt, Leaning further stress analysis, drawn stayed bridge mechanics analysis method.
\end{abstract}

Keywords: Cable force, dorsal column, mechanical analysis, stayed bridge.

\section{INTRODUCTION}

The main part of the cable-stayed bridge is cable, tower, bridge pier, abutment, pier and auxiliary girder. Cable: By the suspension girder, the load transfer to the tower and pier (each tower pier) [1] tower: The structure of a cable supported above a pier can be constructed of reinforced concrete or steel. There are three kinds of connection tower and pier tower and bridge pier consolidation: 1 . Short tower pier consolidation. This structure is good oyerall stability, the main beam fulcrum of the anti - force, the construction is convenient, but the pier at the end of the bending moment. Separate tower and bridge pier. Pylon and girder consolidation and pier separately, referred to as consolidation of tower and beam, can overcome the shortcomings of the pier bottom bending moment is too high, but main beam in the middle fulcrum anti force, large tonnage bridge bearing requirements, causing structural difficulties. The tower is hinged with the pier. It can also reduce the moment of the bottom of pier, but the structural and construction are troublesome, and the overall stability is poor, and is seldom used. Along the axis direction of the tower bridge facade form, commonly used for the column shape or A shape. And the form of the bridge direction is very many, there are double column, door shaped, inverted $\mathrm{V}$ shaped, diamond and single column, etc. arrangement of the tower and the cable on the form. For example, double column and gate are used to set the double parallel cable plane at the main beam, and V - shaped and diamond are used for double inclined cable plane; the single cable plane is

*Address correspondence to this author at the School of Civil Engineering, Shijiazhuang Tiedao University, 17 Northeast, Second Inner Ring, Shijiazhuang, Hebei, 050043, China; E-mail: 46773040@qq.com used for setting up along the middle line of bridge. Double cylindrical door shaped tower construction is convenient; inverted V-shaped construction is trouble-some, and large area foundation, but against the wind stability; diamond to reduce the base area; single cylindrical lightweight form factor, but the main girder must choose torsional stiffness of box section. Main girder: Directly supporting bridge deck and anchoring cable. Its structure form mainly: continuous beam. Overall good, wind resistant, strong earthquake resistance, stiffness, comfort for driving. In the pre stress concrete beam, the influence of the creep and shrinkage of the additional force can be reduced, but the semi suspension system can be greatly reduced. Cantilever beam with hanging holes. The external structure is statically determinate, and can be applied to soft foundation, which can reduce the creep and shrinkage of concrete, but the structural stiffness is poor.. The stress of the cable is bigger than the continuous beam, the deflection is large, and is not conducive to high-speed driving. Frame T rigid. In addition to the cantilever assembly (irrigation and construction) method, the advantages of the same cantilever beam, the disadvantage is that the moment of the pier inside the large. In the form of three structures, the continuous beam is used more. In double span single tower inclined, adopt continuous beam [2]. Auxiliary Pier: The pier in the side hole is used to reduce the deflection, improve the stiffness of the whole bridge, and improve the stress of the main beam, and when the side hole is not high, the auxiliary pier is appropriate.

\section{DESIGN FEATURES OF CABLE-STAYED BRIDGE}

Mainly to meet the wind resistant and seismic requirements, control the deformation of the whole bridge. Firstly, it emphasizes the main hole span and wide ratio of 
not more than 20 , preferably not more than 15 ; followed by the main beam width and height ratio is greater than 8 , shall be greater than 7 and wind mouth, the corresponding cable length is reduced to below 10 meters (to cooperate with construction often take $5 \sim 6$ meters)[3].

In addition, the anti of the wind stability of double inclined cable plane is better than that of double parallel cable plane, and can resist the torsional vibration of the main beam. In the multi tower cable-stayed bridge, such as the use of pre-stressed concrete continuous beam structure, due to the creep and shrinkage of concrete, in the main girder of cable to tension and bending moment, must take the measure to overcome the bridge [4]. In the single tower cable-stayed bridge, the main girder can be freely retractable, and this problem is not generated. In the multi tower cable-stayed bridge, the main girder should be used before closure on the top and even pre storage method to reduce shrinkage and creep. The cable stayed bridge has a certain degree of sag, and it varies with the size of cable force, which affects the stress and deformation of the whole structure [5]. In the large span and cable force change, the impact of large, precision calculation method and electronic computer analysis structure of force. In general, you can wire modified elastic modulus (elastic modulus influence of cable vertical consider simple solution). With the anchor cable anchorage fatigue damage, should be selected with high fatigue strength of anchorage. In the design also need to consider measures to prevent cable corrosion [6].

\section{CALCULATION OF THEORETICAL MECHANICS OF CABLE-STAYED BRIDGE}

The cable-stayed bridge is an indeterminate structures, it is complicated to calculate the internal force of the structure. The structural analysis method has two major categories: One is the classical method is called, the basic method is usually used in mechanical structures, such as the force method, energy method and displacement method. The method can carry out the linear structural analysis of cablestayed bridges, may also be some nonlinear iterative computation. Calculation of cable-stayed bridge structure by using classical method, because the procedure is difficult to achieve the universality, usually by hand calculation is completed. The large span cable-stayed bridge of missile, the calculation of the workload and the difficulty is great [7].

Second kinds of methods are analyzed by computer. First, the spatial structure was simplified as a planar structure, using finite element method, the discretization of the cable structure, with straight bar instead of the flexible cable, note the bending stiffness of the elements is zero, the cable sag effect on deformation by using the method of elastic modulus of concrete to make it linear according to the small deflection theory, (the small deformation theory) structure of the establishment of the total stiffness matrix, the corresponding computer program [8]. Secondly, the spatial structure analysis of the cable-stayed bridge, the finite element method can be adopted, which can be used to simulate the bridge deck system backbone, the II shape model, model of double main beam model, three main modes, the plane truss element analysis [9].

\subsection{Analysis of Plane Finite Element Method}

The cable-stayed bridge is calculated according to the unit such as plane structure, can be divided into cable element and beam element. Cable element is mainly refers to the cable, the cable can be used as a rigid beam element considering. Consider the influence of the stiffness with sag, in order to simplify the calculation, the design of the elastic modulus (Ei) with the straight rod instead of cable. Define the middle point of the cable motion through a number of element nodes, to simulate the nonlinear behavior of cable. In theory, the element number tend to infinity, the real mechanical behavior will tend to stay [10]. The chord direction cable as the element coordinate system, the stiffness matrix is expressed as:

$$
\overline{F_{i j}^{e}}=\overline{K_{i j}^{e}} \overline{\delta_{i j}^{e}}
$$

In the formula:

$\overline{F_{i j}} \longrightarrow$ Rod end load;

$\overline{K_{i j}^{e}} \_$Element stiffness matrix

$\overline{\delta_{i j}^{e}}$ Rod end displacement

Among them, the element stiffness matrix is:

$$
\begin{array}{llll}
\frac{E_{i} A}{l} & 0 & -\frac{E_{i} A}{l} & 0
\end{array}
$$$$
\overline{F_{i j}^{e}}=\begin{array}{cccc}
0 & 0 & 0 & 0 \\
-\frac{E_{i} A}{l} & 0 & \frac{E_{i} A}{l} & 0
\end{array}
$$

In the formula:

A cable work area;

$\mathrm{L} \_$the cable length

Among them, the equivalent elastic modulus of $E$ by Ernst formula modified cable elastic modulus, express:

$$
E_{e q}=\frac{E}{1+\frac{\gamma^{2} l_{c}^{2}}{12 \sigma^{3}} E}
$$

In the formula:

$E_{e q} \longrightarrow$ cable equivalent elastic modulus;

$\gamma \longrightarrow$ cable density;

$E \_$cable material elastic modulus;

$\sigma-$ cable tension stress;

$l_{c}=l \cos \beta-$ lasso of horizontal projection.

Because $\mathrm{E}$ is a function of the cable force, led to the cable end force and displacement of cable end is nonlinear. This is a nonlinear problem is transformed into approximate method for material nonlinearity problems. When the plane 
stress level is low, the precision is low, directly to simulate the cable to get accurate results with flexible cable element.

\subsection{Calculation and Optimization of Cable Force}

Calculation of cable force

The cable concrete cable-stayed bridge as flexible cable, wire rope only outsourcing as protective material, not to participate in the cable force, under the action of self weight of cable under the sag, sag of cable tension performance of cable force, at the same time, also have an impact on the sag [11].

In order to simplify the calculation, in the actual calculation of cable is generally used in the straight rod, cable length as the rod length. The problem is to consider the relationship between the cable sag effect of cable elongation and the axial force effect, the effect of the modified elastic modulus to consider, as the way of calculation:

The geometry equation of cable under dead load

As shown in Fig. (1), a cable no load when the length of $\mathrm{L}$, said the other parameters shown in figure, the cable bending of arbitrary cross section is zero:

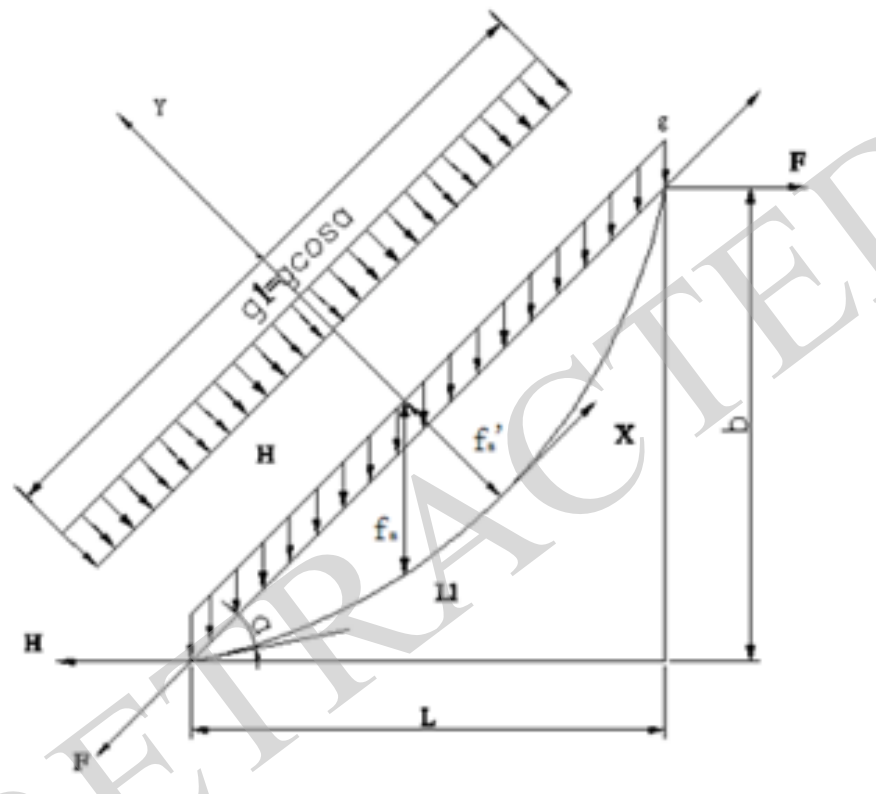

Fig. (1). Stay cable calculation chart.

\subsubsection{Calculation of Stayed Cable}

$$
F \times y=M(x)
$$

$H \times y \times \cos \alpha=M(x)$

$$
\begin{gathered}
y=\frac{M(x)}{H \cos \alpha} \\
\frac{d^{2} y}{d x^{2}}=-\frac{g_{1}}{H \cos \alpha}
\end{gathered}
$$

The fourth type of integral equation can be obtained for the catenary cable geometry.

The cable cross section $X=X_{m}$ :

$F f_{m}^{\prime}=\frac{1}{8} g_{1} l^{2}$

$$
\begin{aligned}
& H=F \cos \alpha \\
& g_{1}=g \cos \alpha, l=L / \cos \alpha \\
& f_{m}^{\prime}=\frac{g L^{2}}{8 H}
\end{aligned}
$$

\subsubsection{Relationship Between Elongation and Sag of Cable}

Cable geometry for the catenary, such as approximate parabola, the cable under the action of gravity length:

$L_{1}=l+\frac{8}{3} \frac{\left(f_{m}^{\prime}\right)^{2}}{l}$

Then the cable is stretched:

$$
\Delta l=L_{1}-l=\frac{g^{2} L^{3} \cos \alpha}{24 H^{2}}=\frac{g^{2} L^{3} \cos ^{2} \alpha}{24 F^{2}}
$$

\subsubsection{Preliminary Determination of Internal Force State of the Bridge}

The internal force state of the bridge is determined at present there are two kinds of methods: Rigid support continuous beam method and Specifies the main stress method, the rigid support continuous beam method is used more [12].

The so-called rigid support continuous beam method is to find a group of dead load cable force, the girder in the role of the dead load and the cable force, cable displacement of beam bridge at the connection point is zero. When the girder dead load bending moment is the moment of rigid support continuous beam. The specific calculation process is as follows:

According to an off the shelf, calculated under dead load cable (cable force is zero) beam at the connection point of the vertical displacement and horizontal displacement at the top of tower $\Delta_{\mathrm{i}}(\mathrm{i}=1,2,3 \mathrm{~L})$. Then calculate the cable force influence on the unit of the amount of $\delta \mathrm{ki}(\mathrm{K}$ node number, I for the cable side.) So in the dead load and the interaction of cable force, so that the vertical displacement of each node is zero for the conditions can be written as linear equations.

$\left[\begin{array}{llll}\delta_{11} & \delta_{12} & \ldots & \delta_{1 n} \\ \delta_{21} & \delta_{22} & L & \delta_{2 n} \\ \delta_{n 1} & \delta_{n 2} & \ldots & \delta_{n 2}\end{array}\right]\left(\begin{array}{l}X_{1} \\ X_{2} \\ X_{n}\end{array}\right)+\left(\begin{array}{l}X_{1} \\ X_{2} \\ X_{n}\end{array}\right)+\left(\begin{array}{c}\Delta_{1} \\ \Delta_{2} \\ \Delta_{n}\end{array}\right)=\left(\begin{array}{l}0 \\ 0 \\ 0\end{array}\right)$

The method is to analysis the reasonable finished dead state of the most original, the most intuitive, the method to determine the bending moment is very small, but the cable force can jump very uneven, obviously, and the moment of the asymmetric tower difficult to consider, if necessary, The rigid support continuous beam is improved.

\subsubsection{Cable Force Optimization}

Cable-stayed bridge cable force is adjustable, how to determine the reasonable cable force of cable-stayed Bridge design, construction, and operation, maintenance issues, optimization of cable force is usually used for the influence matrix method into the optimization of cable force state of 
the bridge. In the structure of system is clear, as the value of the bridge cable tension will greatly affect the cable-stayed bridge stress state rationality. In order to make the cablestayed bridge and the stress state of the most reasonable, can be in the stage of conceptual design, preliminary design and construction drawing design of cable force optimization.

Optimization method of cable force specified stress state, the rigid support beam method and the zero displacement method as the representative. Rigid support continuous beam method of main girder of cable-stayed bridge under dead load bending moment is rigid support continuous girder as optimization objectives. Zero displacement method to structure in the node displacement under the action of dead load beam is zero as the optimization goal. Unconstrained optimization method is the minimum bending energy method and the minimum bending moment method of cable of cable force, minimum bending energy method is used for the bending energy as the objective function; the minimum bending moment method is used as the objective function in the square. Cable force of constrained optimization method with the minimum amount of cable minimum method and the maximum deviation method, the minimum amount of the cable is a cable stayed bridge cable (cable length multiplied by the amount of tension) as the objective function, the internal force, displacement with care section of expected value as constraint condition; the maximum deviation method of minimum deviation parameters and the feasible the expected value in the domain as the objective function, the maximum error reaches the minimum.

Usually, the reasonable finished bridge state of cablestayed bridge to meet: cable force distribution, the moment of tower can not be too large, the stress should be controlled in the scope of "feasible", pier bearing force under constant load to reserve enough pressure, the stress of main girder, the most key.

\subsubsection{The Construction Stage Cable Force Optimization}

Optimization of cable force of cable-stayed bridge construction is not only to make the stress state of the bridge is more reasonable, but also to ensure the safety of the construction phase of the force. According to the inverse process of construction, it can satisfy the bridge internal force optimization condition, internal force state of each construction stage and configuration, which ideal state for construction stage. But in actual construction, the component weight, stiffness, construction precision, cable tension error, temperature and other factors, the actual state of construction stage of a serious deviation from the ideal state. On the optimization of cable force adjustment is an important means of correcting the construction stage. A method commonly used in engineering is the appropriate adjustment of cable force, the maximum deviation of concern on the section of the control variables to reduce. The displacement of variable control in the construction process of the bridge, it is under the condition of control variables to the internal force and the cable force.

\section{MECHANICAL ANALYSIS AND ENGINEERING EXAMPLE THE LEANING TOWER OF CABLE- STAYED BRIDGE}

\subsection{Stress Analysis of the Leaning Tower of Cable- Stayed Bridge}

The Leaning Tower of cable-stayed bridges have been built, part of the dorsal cable, a part of no back stays, the method of force analysis is consistent: it is the control tower section moment minimum. Without back cable tower by tower weight to balance the load of the main girder, the tower of Hong Shan bridge balance calculation. If the tower beam segment weight WT and the load of P beam is simplified as concentrated force acting on the anchorage point (shown in Fig. 2), In order to make the structure in the stress state of the ideal, namely tower, beam, cable three parts in the axial force, balance the relationship between the weight of the cable bridge tower segment, the loads and the girder segment of the:

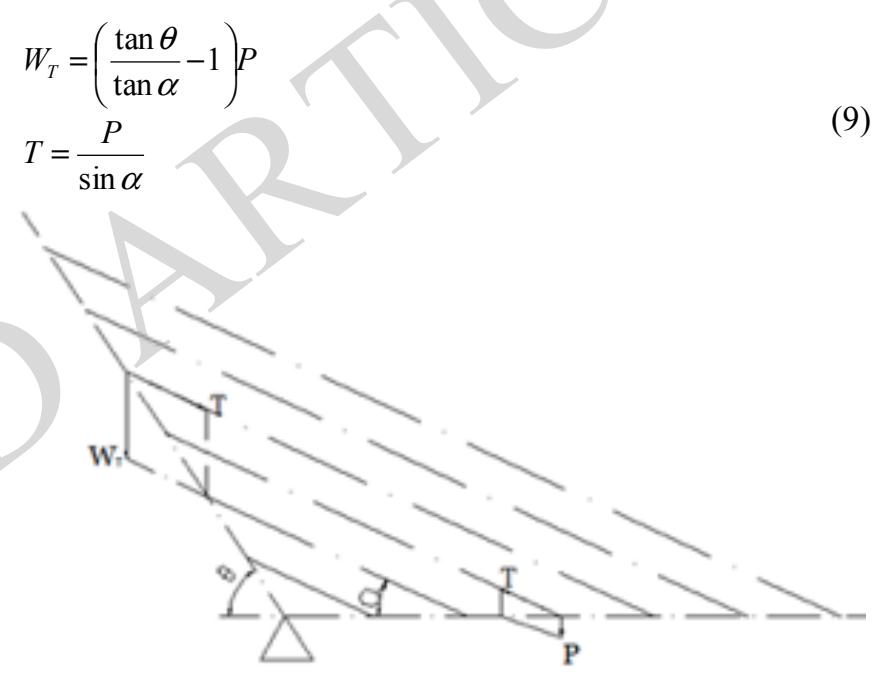

Fig. (2). Equilibrium calculation chart of tower beam.

\subsubsection{Calculation of the Tower Beam Balance (2)}

Back in a cable stayed bridge, the span of weight or ballast to balance the main tower. And through the back of main tower, can reduce the side spans load, reduce the weight of structure, so as to optimize the stress of the whole structure, thus, to accurately determine the back angle.

\subsection{Influence of the Inclination of the Tower Structure}

The biggest feature is the tower of Pisa: The beam body weight through the core concrete main tower and the tower weight for ward to balance, the cable force and the core concrete weight adjustment to the structural shape, strength and stability meet the design requirements. Therefore, leaning angle has great influence on the stress of structures. To Ban Fu No. 2 bridge as an example (see Fig. 3 below). On the in-depth and detailed analysis of the parameters, analysis 
results show that: the optimal economic status and structure of the total material expenditure structure stress almost at the same time, at this time, the tower after the elevation is about $13.5^{\circ}$.

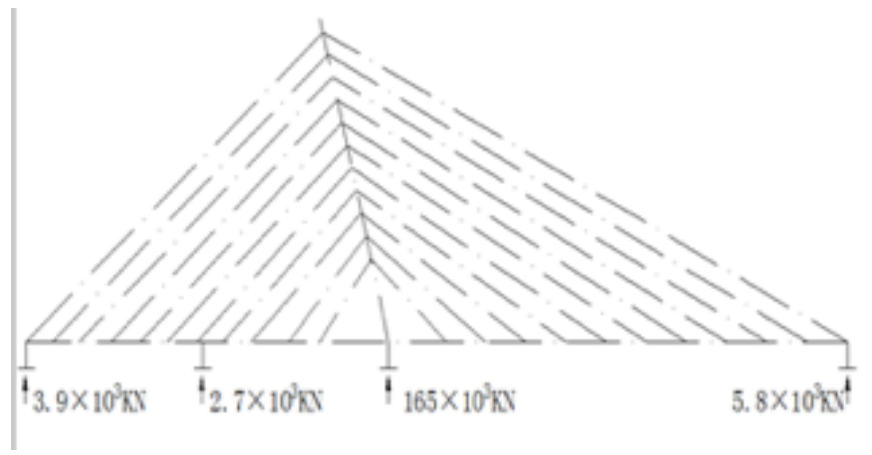

Fig. (3). Ban Fu bridge to try.

The figure can be found:

Above and below the compression state of the master node at the pier tower girder fixed, so the durability of the structure of the local structure, the use of good; the main pier of bridge without horizontal shear, axial force only when included in the components, the horizontal direction is close to equilibrium (node unbalanced force is $1.9 \mathrm{Mn}$, the value of shear, tower unit figure not shown), indicating pylon cablestayed bridge structure affected by the compression based force (at least in the finished state of the bridge) in this structure is fully realized;

Because the inclined tower, the angle between the cable and the side span of main tower of the center line of the main span side is always greater than the angle, the angle from the end to the internal rope around 12. - 3.5. The structure have the very favorable capacity and economic.

\subsection{The Analysis of Engineering Example}

Similarly to the Ban Fu No.2 bridge as an example, the cable force of cable-stayed bridge tower is mainly composed of the main tower and the bridge deck structure weight to balance the weight determination method of cable force, so different from the upright pylon cable-stayed bridge main girder internal force, not only need to control the internal force of tower column, also need to control, so the Ban $\mathrm{Fu}$ No.2 bridge girder and the double control cable adjustment to ultimately determine the cable force of cable-stayed bridge, the reasonable state of cable force distribution are listed in the following Table $\mathbf{1 .}$

Table "s" for the side span, according to a cable from the internal cables are prepared, "M" main span side, also from the internal cables and a cable are compiled. As shown in the cable force distribution table.

The edge of the cross in the cable force, and to both sides will be increased.

The main span of cable force from outside to inside increased;

The cable force of the main span cable is larger than that of the corresponding side span cable.

Cable force distribution can be understood for:
(1) The side span is the dorsal, and near the pier and is located in the auxiliary cable auxiliary pier, bridge load part borne by the auxiliary pier, so the cable force;

(2) The small angle between the main span and small internal rope tower, the effects of weight cable need to balance the tower, but is instead;

(3) The main span is the positive side, the need to balance the effect of gravity due to the tilt of the tower.

Table 1. The bridge cable tower of cable force of single exit list.

\begin{tabular}{|c|c|c|c|}
\hline Number & Cable Force (KN) & Number & Cable Force (KN) \\
\hline \hline S1 & 1380.3 & M1 & 1153.4 \\
\hline S2 & 1079.3 & M2 & 1072.4 \\
\hline S3 & 1423.1 & M3 & 1295.1 \\
\hline S4 & 1061.8 & M4 & 1439.8 \\
\hline S5 & 1034.2 & M5 & 1487.7 \\
\hline S6 & 971.5 & M6 & 1671.9 \\
\hline S7 & 870.1 & M7 & 1679.5 \\
\hline S8 & 1023.3 & M8 & 1766.7 \\
\hline S9 & 1959.9 & M9 & 2027.4 \\
\hline S10 & 2018.8 & M10 & 2439.0 \\
\hline S11 & 2017.4 & M11 & 2350.0 \\
\hline S12 & 2141.4 & M12 & 2368.5 \\
\hline S13 & 2086.5 & M13 & 2573.2 \\
\hline S14 & 2184.3 & M14 & 2521.4 \\
\hline S15 & 2428.1 & M15 & 2598.3 \\
\hline
\end{tabular}

\section{CONCLUSION}

By the introduction of visible, this kind of bridge is novel and unique, rich and strong force of feeling, but also very soft, simple, but because of the design and construction of inclined tower, the difficulty, the design calculation of the difficulty lies in the angle of the commonly used method is determined, according to the domestic and foreign have been built in the same bridge to determine a range, and then different angles of trial in this range, concluded that the best angle. The influence of cable force is the angle of the tower structure. The cable force decreases with the increase of the leaning tower obliquity, because the smaller the angle, the greater the gravity moment of inertia, in order to maintain the balance of the tension cable, need more requirements, the stiffness of the girder is also higher. From an economic point of view, change in the stiffness of the girder and the weight of the case, the weight of the tower in the change of column axial compression state, the inclination of the tower the tower, the more weight, the required materials are also more and more, but on the other hand, the greater the inclination of the tower, cable length is small, the amount of steel required less. Under normal circumstances, the tower beam stress in roughly the same case, the inclination of the tower, the weight will. 


\section{CONFLICT OF INTEREST}

The authors confirm that this article content has no conflict of interest.

\section{ACKNOWLEDGEMENTS}

Declared none.

\section{REFERENCES}

[1] C. F. Daganzo, "The cell transmission model: A dynamic representation of highway traffic consistent with the hydrodynamic theory," Transportation Research Part B: Methodological, vol. 28, no. 4, pp.269-287, 1994.

[2] F. Lichu, "Bridge Engineering, "Beijing: people traffic press,1993.

[3] Z. Wu, and X. Gui,"Adaptive control of pre-stress concrete cablestayed bridge construction," Engineering Mechanics, vol. 5, no.2, pp. 11-25,2006.
[4] W. Peng, X. Shao, L. Li, and Y. Zhang "The concept, design and construction of the cable-stayed bridge without Backstays," Journal of Civil Engineering, vol. 40, no.7, pp. 10-25,2007.

[5] D. C. Shun, "The finite element method," Beijing: Peking University press,.2006.

[6] X. G. Fan, and X. Cheng, "Cable tension optimization and its engineering application," Computational Mechanics, vol. 15, no.1, pp.118-126, 1998.

[7] G. Min, "Modern cable-stayed bridge," Southwest Jiao Tong University press, 1996.

[8] G. Ming, "Constitution, high way bridge construction technology of cable-stayed bridge,"People's Communications Press, 2003

[9] Z. Zhiyong, "The cable-stayed bridge cable force Chinese test," Journal of Highway and Transport," vol.10, no. 1, pp. 51-58, 1997.

[10] S. Hu, and A. Ye, "Research on seismic structure system of cablestayed bridge," Bridge Construction, vol. 4, pp. 1-4, 2002.

[11] G. Du, and J. Lin, "Cable-stayed bridge, reasonable cable force and its construction tension," Bridge Construction, vol. 3, no.1, 1989.

[12] L. Qiao, "Geometric nonlinear effect of deformation of extra large span cable-stayed bridge," Journal of Engineering, vol. 21, no.7, pp. 12-28, 2011.

Received: May 26, 2015

Revised: July 14, 2015

Accepted: August 10, 2015

(C) Tie and Ruichuan; Licensee Bentham Open.

This is an open access article licensed under the terms of the (https://creativecommons.org/licenses/by/4.0/legalcode), which permits unrestricted, non-commercial use, distribution and reproduction in any medium, provided the work is properly cited. 